\title{
Murrayanine-1, 3, 4-Thiadiazole-Uracil Hybrid as Emerging Anti-inflammatory Candidate
}

\author{
Debarshi Kar Mahapatra $^{1 \star}$, Kanhaiya M Dadure ${ }^{2}$ and Ruchi S Shivhare ${ }^{3}$ \\ ${ }^{1}$ Department of Pharmaceutical Chemistry, Dadasaheb Balpande College of Pharmacy, Nagpur 440037, Maharashtra, India \\ ${ }^{2}$ Department of Chemistry, J. B. College of Science, Wardha 442001, Maharashtra, India \\ ${ }^{3}$ Department of Pharmaceutical Chemistry, Kamla Nehru College of Pharmacy, Nagpur 441108, Maharashtra, India
}

\section{Article Info}

\section{*Corresponding author: Debarshi Kar Mahapatra} Assistant Professor

Department of Pharmaceutical Chemistry Dadasaheb Balpande College of Pharmacy Nagpur 440037, Maharashtra India

Tel: +91917232 2500

Email: dkmbsp@gmail.com

\section{Received: July 23, 2018}

Accepted: September 17, 2018

Published: September 22, 2018

Citation: Mahapatra DK, Dadure KM, Shivhare RS. Murrayanine-1, 3, 4-ThiadiazoleUracil Hybrid as Emerging Anti-inflammatory Candidate. Madridge J Nov Drug Res. 2018; 2(1): 75-78

doi: $10.18689 /$ mjndr-1000111

Copyright: (c) 2018 The Author(s). This work is licensed under a Creative Commons Attribution 4.0 International License, which permits unrestricted use, distribution, and reproduction in any medium, provided the original work is properly cited.

Published by Madridge Publishers

\begin{abstract}
Inspiring and motivating from the above fact that hybridization by incorporating several heterocyclic scaffolds often results in amplification of pharmacological activity, a hybrid was fabricated which contains murrayanine (an active carbazole obtained from Murraya koenigii L.), 1,3,4-thiadiazole, and uracil scaffold and was further screened for its anti-inflammatory potential by using carrageen an-induced paw edema method. The synthesis involved reaction of 5-(1-methoxy-9H-carbazol-3-yl)-1,3,4-thiadiazol-2-amine with uracil (6-(chloromethyl)pyrimidine-2,4(1H,3H)-dione). As compared to the previously reported murrayanine-thiadiazole derivative, the introduction of the uracil component resulted in an enhancement in the in vivo inflammatory activity in carrageenan-induced paw edema model (46.88\%). The amplified edema reducing perspective of the novel fabricated hybrid may be due to the interaction of the amide and carbonyl groups with the active site of the inflammatory mediators such as COX and LOX. The present work will surely provide a motivation to the medicinal chemists in the judiciously designing of lowmolecular-weight ligands with pronounced anti-inflammatory activity.
\end{abstract}

Keywords: Anti-inflammatory; Hybrid; Murraya koenigii; Murrayanine; Thiadiazole; Uracil

\section{Introduction}

The Asian origin plant, Indian curry plant, also known as Murraya koenigii L. (Family Rutaceae) finds ethnopharmacological application as stomachic, anthelmintic, purgative, anti-anemic, febrifuge, carminative, and astringent [1]. Murrayanine, the most active and the highly explored carbazole phytoconstituent has been reported to exhibit pharmacological activities like anti-oxidant, anti-bacterial, anti-fungal, antiseptic, etc [2]. Very recently, our group has reported several semi-synthetic murrayanine hybrids such as phthalimide [3], pyrimidine [4], pyrazole [5], chalcone [6], hydroxylated chalcone [7], hydantoin [8], thiazole [9], thiadiazole [10], isoxazole [11], oxadiazole [12], benzodiazepine [13], benzoxazepine [14], benzothiazepine [15], Schiff's base derivative [16], and 3,4-methylenedioxy [17], methylsulfone [18] which predominantly expressed amplified biological responses such as anti-oxidant, antibacterial, anti-fungal, anti-anxiety, antidiabetic, anti-convulsant, and anti-inflammatory, by using the implementation of the most successful strategy 'hybridization'.

1,3,4-Thiadiazole is one of the most popular heterocycle scaffold having several drug candidates in the market. Experimentally, a number of applications have been reported such as anti-leishmanial, anti-tubercular, anti-viral, anti-trypanosomal, anti-retroviral, anti-cancer, anti-diabetic, anti-bacterial, anti-fungal, anti-arrhythmic, anti-hypertensive, anti-inflammatory, anti-nociceptive, anti-ulcer, etc [19]. In the previous report, murrayanine-1, 3, 4-thiadiazole had been prepared with an intention of expressing better anti-inflammatory activity [10]. 
The uracil is a vital component in the human body which has specified function in the formation of DNA. Uracil finds applications in the area of medicinal chemistry where it has been reported as anti-varicella zoster [20], anti-HIV-1 [21], antihepatitis B [22], anti-herpes [23], anti-Epstein-Barr [24], anticancer [25], etc. At present, only one paper has been reported in the area of inflammation where uracil finds application as edema reducing agent [26]. It has been observed that hybridization by incorporating several heterocyclic scaffolds often results in amplification of pharmacological activity [27].

Inspiring and motivating from the above fact, a hybrid was fabricated which contains murrayanine, 1,3,4-thiadiazole, and uracil scaffold and was further screened for its antiinflammatory potential by using carrageenan-induced paw edema method.

\section{Materials and Methods}

\section{Chemical and Instrumentation}

The reactant 6 -(chloromethyl) pyrimidine- $2,4(1 H, 3 H)$ dione [2] was procured from Sigma-Aldrich ${ }^{\circledR}$, Germany through a local vendor. The starting material 5-(1-methoxy$9 H$-carbazol-3-yl)-1,3,4-thiadiazol-2-amine [1] was obtained from our previous research report [10]. The elemental analysis was performed on Elemental Analyzer (Perkin-Elmer 240C). Merck $^{\oplus}$ thin layer chromatography silica gel G-coated plates were used monitoring the progress of the chemical reaction. The final compound was characterized for confirming the proposed structure through Fourier-transformed infrared (FT-IR) using the $\mathrm{KBr}$ discs (IRAffinity-1), ${ }^{1} \mathrm{H}$ (proton)-NMR employing tetramethylsilane as the internal standard at 400 $\mathrm{MHz}$ (Bruker spectrospin NMR DPX-300 instrument), and mass spectra by employing JEOL-JMS-DX 303 instrument.

\section{Animals}

The anti-inflammatory potential of the novel compound was screened in Swiss male albino rat after procuring permission from CPCSEA (1389/a/10/CPCSEA) and Department Ethical Committee (DEC). The experimental animal had 5-7 week age and 150-250g weight. The animals were kept in the animal house under controlled environment (24-25 $5^{\circ} \mathrm{C}$ temperature, $50-60 \%$ humidity, and $12 \mathrm{hr}$ cycle of light and dark). The rodents were provided free access to water and fed standard rodent pellets.

\section{Synthesis of target compounds}

The reaction involves reacting 5-(1-methoxy- $9 \mathrm{H}$ carbazol-3-yl)-1,3,4-thiadiazol-2-amine [1], the starting material with 6 -(chloromethyl)pyrimidine-2,4(1H,3H)-dione [2], the reactant at room temperature in the presence of triethylamine to obtain 6-(((5-(1-methoxy-9H-carbazol-3-yl)1,3,4-thiadiazol-2-yl)amino)methyl)pyrimidine-2,4(1H,3H)dione [3]. In this chemical reaction, the amine part gets transformed into the corresponding amide where a proton gets abstract from the compound [1] and chloride from the compound [2], thereby forming $\mathrm{HCl}$ (hydrochloride). The added triethylamine (also a good nucleophile) in the media helped in maintaining the neutrality. The outline of the chemical reaction is mentioned in Scheme 1.

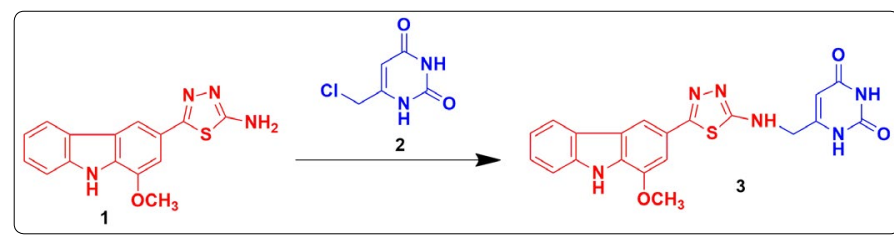

Scheme 1. Synthesis outline of murrayanine-thiadiazole-uracil hybrid.

Synthetic protocol for 6-(((5-(1-methoxy-9H-carbazol-3-yl)-1,3,4thiadiazol-2-yl)amino)methyl) pyrimidine-2,4(1H,3H)-dione [3].

In a three-neck flask equipped with a stirrer, $0.01 \mathrm{M}$ of 5-(1-methoxy-9H-carbazol-3-yl)-1,3,4-thiadiazol-2-amine [1] was added and dissolved in the ethanol-methanol mixture. Triethylamine was added dropwise to the above content and stirred for 20 minutes duration at high RPM. Subsequently, equimolar quantity of 6 -(chloromethyl)pyrimidine-2,4 $(1 H, 3 H)$ dione [2] (methanolic solution) was added and the reaction content was made to stir for an hour at low RPM. The final product was poured on crushed ice in a thin stream to afford separation of the solid product, which was further washed thoroughly, dried completely, and recrystallized.

$79 \%$ yield; FTIR $(\mathrm{KBr}) \cup\left(\mathrm{cm}^{-1}\right): 3129$ (-NH, stretching), 3038 $(\mathrm{C}-\mathrm{H}$, aromatic) $1754(\mathrm{C}=\mathrm{O}$, stretching $), 1671(\mathrm{C}=\mathrm{N}$, fivemembered), 1645 ( $\mathrm{C}=\mathrm{C}$, aromatic), 1531 (-NH, bending), 1467 (- $\mathrm{CH}_{2^{\prime}}$ bending), 1304 (C-N, stretching), 1272 (C-O, stretching); ${ }^{1} \mathrm{H}$ NMR $\left(\delta, \mathrm{ppm}, \mathrm{CDCl}_{3}\right): 10.23$ (9, Carbazole, $\left.1 \mathrm{H}\right), 10.16(18$, Uracil Amide, 1H), 7.1-7.9 (Aromatic, 5H), 6.19 (16, Uracil Amide, 1H), 4.28 (13, Amide, 1H), 4.13 (14, Methylene, 2H), $3.74(1,3 \mathrm{H})$. MS: $\mathrm{M}^{+} 420$. Anal. Calcd. for $\mathrm{C}_{20} \mathrm{H}_{16} \mathrm{~N}_{6} \mathrm{O} 3 \mathrm{~S}$ : C, 57.13; $H, 3.84 ; N$, 19.99. Found: $C, 56.61 ; H, 3.33 ; N, 19.13$

\section{Anti-inflammatory screening}

The in vivo anti-inflammatory potential was explored by using carrageenan-induced paw edema method using indomethacin $(10 \mathrm{mg} / \mathrm{kg})$ as the positive control. Before the commencement of the experiment, the Swiss albino rats were fasted overnight to remove any sort of inconsistency in edema. Individually, $5 \mathrm{~mL}$ of distilled water was given to all rats before initiating the protocol. The compound (3) was screened by orally administering (at dose of $100 \mathrm{mg} / \mathrm{kg} \mathrm{b.w.)}$ $1 \mathrm{hr}$ before the initiation of inflammation. The control group received the saline solution $(0.9 \%)$ containing solubilizer (a few drops of Tween 80). The inflammation was generated by injecting $1 \%$ carrageenan solution at the subplanter region of the right hind paw of rats via the subcutaneous route. The thickness of each rat paw was duly evaluated by mercury digital micrometer for the duration of $3 \mathrm{hrs}$ with an interval of $1 \mathrm{hr}$. The difference between the width of injected and noninjected paws was estimated for the determination of antiinflammatory potential. The obtained results were expressed as the Mean \pm SEM [28]. 


\section{Statistical treatment}

The data were statistically analyzed by one-way ANOVA approach followed by Dunnett's multiple comparison tests. The $P<0.01$ value was considered to be the most statistically significant.

\section{Result and Discussion}

\section{Chemistry}

The sophisticated spectroscopic applications certainly helped in the confirmation of the proposed hybrid derivative [3]. The attachment of the uracil component [2], with the murrayanine-thiadiazole [1] was ascertained from the fact that the amine component $\left(-\mathrm{NH}_{2}\right.$ peak) vanished from the FT-IR spectra of compound [3], which was present earlier at $3316 \mathrm{~cm}^{-1}$. In addition to it, the $\mathrm{C}-\mathrm{N}$ part between the thiadiazole linked amide and methylene carbon was observed at $1304 \mathrm{~cm}^{-1}$. Moreover, the amide portion at position 13 was observed at 4.28 ppm in the NMR spectrum, which supported the fabrication of the hybrid. The formation of amide was additionally confirmed from the $-\mathrm{CH}_{2}$ - linkage as observed in FT-IR spectrum at 1467 $\mathrm{cm}^{-1}$ and in ${ }^{1} \mathrm{H}-\mathrm{NMR}$ at $4.13 \mathrm{ppm}$. The $-\mathrm{NH}$ components in uracil scaffold or the carboxamide $\mathrm{NH}$ of uracil at positions 16 and 18 were chiefly located at $6.19 \mathrm{ppm}$ and $10.16 \mathrm{ppm}$ in the protonNMR spectrum. The presence of the carbazole was confirmed by the presence of two aromatic rings in the range of 7.1-7.9 ppm. Furthermore, the $\mathrm{C}-\mathrm{H}$ and $\mathrm{C}=\mathrm{C}$ of the aromatic ring were predominantly seen at $3038 \mathrm{~cm}^{-1}$ and $1645 \mathrm{~cm}^{-1}$, respectively. The carbazole - NH was substantiated from the NMR spectra at $10.23 \mathrm{ppm}$. The five-membered heterocycle was authenticated from the ring $\mathrm{C}=\mathrm{N}$ component at $1671 \mathrm{~cm}^{-1}$. The mass spectra showed that the base peak corresponds to the theoretical molecular mass (420), also with the emergence of numerous fragment peaks. The \% composition of the elements matched in closed agreement with that of the theoretically calculated values.

\section{Anti-inflammatory screening}

The developed murrayanine-thiadiazole-uracil hybrid [3] demonstrated noteworthy anti-inflammatory activity in carrageenan-induced paw edema model with \% edema reducing potentials of $23.63,37.07$, and 46.88 , respectively in the three consecutive hrs (Table 1). On comparing the anti-inflammatory results of previously reported murrayanine-thiadiazole derivative, it was found that substitution of uracil marginally improved the edema reducing aspect. The augmentation of edema reducing activity may be due to the interaction of the amide and carbonyl groups with the active site of the inflammatory mediators such as cyclooxygenase (COX) and lipoxygenase (LOX) [29].

Table 1. In vivo anti-inflammatory potential of murrayanine-thiadiazoleuracil hybrid in carrageenan-induced paw edema rat model.

\begin{tabular}{|l|l|l|l|}
\hline Compound & \multicolumn{3}{l|}{ Percentage (\%) inhibition of edema } \\
\hline & $1 \mathrm{hr}$ & $\mathbf{2} \mathrm{hr}$ & $3 \mathrm{hr}$ \\
\hline $\mathbf{3}$ & $23.63^{\star} \pm 2.14$ & $37.07^{\star \star} \pm 1.66$ & $46.88^{\star} \pm 2.33$ \\
\hline Indomethacin & $38.76^{\star} \pm 2.94$ & $50.14^{\star \star} \pm 1.81$ & $72.92^{\star \star} \pm 2.57$ \\
\hline
\end{tabular}

$\mathrm{n}=6$; $E D_{50}$ of $100 \mathrm{mg} / \mathrm{kg}$ b.w. in male adult albino mice;

Indomethacin (10 mg/kg b.w.)

${ }^{* * P}<0.01 ;{ }^{*} \mathrm{P}<0.05$

\section{Conclusion}

The current research highlighted the importance of hybridization of various crucial scaffolds in a single molecule. As compared to the previously reported murrayanine-thiadiazole derivative, the introduction of the uracil component resulted in an enhancement in the in vivo inflammatory activity in carrageenan-induced paw edema model (46.88\%). The amplified edema reducing perspective of the novel fabricated hybrid may be due to the interaction of the amide and carbonyl groups with the active site of the inflammatory mediators such as COX and LOX. The present work will surely provide a motivation to the medicinal chemists in the judiciously designing of low-molecularweight ligands with pronounced anti-inflammatory activity.

\section{Acknowledgement}

Authors are highly thankful to Savitribai Phule Pune University, Pune, Maharashtra, India for providing research grants (Grant No. 13PHM000126).

\section{References}

1. Handral HK, Pandith A, Shruthi SD. A review on Murraya koenigii: multipotential medicinal plant. Asian J Pharm Clin Res. 2012; 5(4): 5-14.

2. Shivhare RS, Mahapatra DK, Nair RR, Deshmukh SN. Schiff's base derivatives of murrayanine demonstrated enhanced anti-oxidant activity than its parent moiety. Indian J Pharm Edu Res. 2016; 50(4): 9-15. doi: 10.5530/ijper.50.4.12

3. Mahapatra DK, Shivhare RS. Synthesizing an anti-oxidant principle 2-(((1-methoxy-9H-carbazol-3-yl)methylene)amino)isoindoline-1,3dione from $\mathrm{N}$-aminophthalimide and murrayanine. Inventi Med Chem. 2017; 2017(4): 1-3.

4. Mahapatra DK, Shivhare RS, Kumar P. Murrayanine-chalcone transformed into novel pyrimidine compounds demonstrated promising antiinflammatory activity. Asian J Pharm Res. 2018; 8(1): 6-10. doi: 10.5958/2231-5691.2018.00002.3

5. Mahapatra DK, Shivhare RS, Bharti SK. Novel Murrayanine based Pyrazole analogs as emerging anti-fungal candidates: Design, synthesis, characterization, and in vitro evaluation. Res Pharm. 2017; 1(1): 1-5.

6. Mahapatra DK, Chhajed SS, Shivhare RS. Development of MurrayanineChalcone hybrids: An effort to combine two privilege scaffolds for enhancing hypoglycemic activity. Int J Pharm Chem Anal. 2017; 4(2): 30 34. doi: 10.18231/2394-2797.2017.0008

7. Mahapatra DK, Dadure KM, Shivhare RS. Exploring the Site-Specific Influence of Hydroxyl group in Ring-B of Murrayanine-Chalcone on Edema Reducing Potential. MOJ Drug Des Devel Ther. 2018; 2(4): 191-194. doi: 10.15406/mojddt.2018.02.00046

8. Mahapatra DK, Das D, Shivhare RS, Borkar SS. Murrayanine-hydantoin and -thiohydantoin analogs as promising anti-convulsant agents: Synthesis, Characterization and Molecular Docking Studies. MOJ Bioorg Org Chem. 2018; 2(2): 47-51. doi: 10.15406/mojboc.2018.02.00055

9. Mahapatra DK, Das D, Shivhare RS. Substituted thiazole linked murrayanine-Schiff's base derivatives as potential anti-breast cancer candidates: Future EGFR Kinase inhibitors. Int J Pharm Sci Drug Res. 2017; 9(3): 139-144. doi: 10.25004/IJPSDR.2017.090307

10. Mahapatra DK, Shivhare RS, Haldar AGM. Novel Schiff's base containing Murrayanine-1,3,4-Thiadiazole Hybrids as potential anti-inflammatory agents. Asian J Chem Pharm Sci. 2017; 2(2): 10-15. doi: 10.18311/ ajcps/2017/20002

11. Mahapatra DK, Shivhare RS, Joseph TM. Design and characterization of Murrayanine linked Isoxazole derivatives: Novel class of bacteriocidal agents. Int J Res Drugs Pharm Sci. 2017; 1(1): 11-15. 
12. Mahapatra DK, Shivhare RS, Ugale VG. Anti-inflammatory potentials of some novel Murrayanine containing 1,3,4-Oxadiazole derivatives. Asian J Pharm Technol. 2018; 8(1): 47-51. doi: 10.5958/2231-5713.2018.00008.9

13. Mahapatra DK, Shivhare RS, Dadure KM. Transforming MurrayanineChalcone into corresponding $3 \mathrm{H}$-benzo[b][1,4]diazepine derivatives: Accessing the anti-anxiety effect by inhibition of locomotor activity. Acta Sci Pharm Sci. 2018; 2(5): 40-44.

14. Mahapatra DK, Shivhare RS, Gupta SD. Anxiolytic activity of some 2,3-dihydrobenzo[b][1,4]oxazepine derivatives synthesized from Murrayanine-Chalcone. Asian J Res Pharm Sci. 2018; 8(1): 25-29. doi: 10.5958/2231-5659.2018.00006.1

15. Mahapatra DK, Shivhare RS, Asati V. Locomotor inhibitory activity of some Murrayanine-Chalcone based 2,3-dihydrobenzo[b][1,4]thiazepine derivatives: Exploring Anxiolytic potentials. Chron Pharm Sci. 2018; 2(1): 462-468.

16. Mahapatra DK, Dadure KM, Shivhare RS. Edema Reducing Potentials of Some Emerging Schiff's bases of Murrayanine. MOJ Bioorg Org Chem. 2018; 2(4): 172-175. doi: 10.15406/mojboc.2018.02.00076

17. Mahapatra DK, Shivhare RS. 3',4'-Methylenedioxy Moiety Containing Murrayanine Based Chalcone as Emerging Anti-inflammatory Agent. J Modern Chem Chem Technol. 2018; 9(1): 12

18. Mahapatra DK, Shivhare RS. Anti-microbial Perspective of a Chalcone, (E)1-(1-methoxy-9H-carbazol-3-yl)-3-(4-(methylsulfonyl)phenyl)prop-2-en1-one: Fabrication of a Hybrid by Unification of a Natural Product with a Synthetic Component. Int J Agri Life Sci. 2018; 4(2): 236-240. doi: 10.22573/ spg.ijals.018.s12200090

19. Mishra G, Singh AK, Jyoti K. Review article on 1, 3, 4-thiadiazole derivatives and its pharmacological activities. Int J Chem Tech Res. 2011; 3: 1380-1393.

20. Onishi T, Mukai C, Nakagawa R, Sekiyama T, Aoki M, et al. Synthesis and antiviral activity of novel anti-VZV 5-substituted uracil nucleosides with a cyclopropane sugar moiety. J Med Chem. 2000; 43(2): 278-282.
21. Maruyama $T$, Kozai $S$, Demizu $Y$, Witvrouw $M$, Pannecouque $C$, et al Synthesis and anti-HIV-1 and anti-HCMV activity of 1-substituted 3-(3, 5-dimethylbenzyl) uracil derivatives. Chem Pharm Bull. 2006; 54(3): 325333.

22. Staschke $K A$, Colacino JM, Mabry $T E$, Jones $C D$. The in vitro anti-hepatitis $B$ virus activity of FIAU [1-(2'-deoxy- 2 '-fluoro- $1-\beta$ - $d$-arabinofuranosyl-5iodo) uracil] is selective, reversible, and determined, at least in part, by the host cell. Antiviral Res. 1994; 23(1): 45-61.

23. Suzutani T, Machida H, Sakuma T, Azuma M. Effects of various nucleosides on antiviral activity and metabolism of 1-beta-D-arabinofuranosyl-E-5-(2bromovinyl) uracil against herpes simplex virus types 1 and 2. Antimicrob Agent Chemother. 1988; 32(10): 1547-1551.

24. Lin JS, Kira T, Gullen E, Choi Y, Qu F, et al. Structure- Activity Relationships of I-Dioxolane Uracil Nucleosides as Anti-Epstein Barr Virus Agents. J Med Chem. 1999; 42(12): 2212-2217. doi: 10.1021/jm9806749

25. Kumar K, Sagar S, Esau L, Kaur M, Kumar V. Synthesis of novel 1H-1, 2, 3-triazole tethered C-5 substituted uracil-isatin conjugates and their cytotoxic evaluation. Eur J Med Chem. 2012; 58: 153-159. doi: 10.1016/j. ejmech.2012.10.008

26. Isobe $Y$, Tobe $M$, Inoue $Y$, Isobe $M$, Tsuchiya $M$, et al. Structure and activity relationships of novel uracil derivatives as topical anti-inflammatory agents. Bioorg Med Chem. 2003; 11(23): 4933-4940.

27. Mahapatra DK, Bharti SK. Handbook of Research on Medicinal Chemistry. New Jersey: Apple Academic Press, 2017.

28. Amdare MD, Jogdand KR, Kathane LL, Kuhite NG, Mahapatra DK, et al. Synthesis of a potential anti-inflammatory pyrazole derivative from hippuric acid as the starting material. J Pharm Chem Biol Sci. 2017; 5(3): 1-5.

29. Joseph TM, Sharanya CS, Mahapatra DK, Suresh KI, Sabu A, et al. In vitro Assessment of Selected Benzoic Acid Derivatives as Anti-inflammatory Compounds. J Sci Indus Res. 2018; 77(6): 330-336. 